\title{
Erratum to: Discretion at the Pre-Trial Stage: A Comparative Study
}

\author{
D. H. Choe
}

Published online: 1 April 2014

(C) Springer Science+Business Media Dordrecht 2014

\section{Erratum to: Eur J Crim Policy Res (2014) \\ DOI 10.1007/s10610-013-9216-4}

Since publication of this paper, the affiliation of the author Dae-Hyun Choe has changed. The new affiliation is Konkuk University with address 268 Chungwon-Daero, Chungju, 380-701, South Korea. The new contact e-mail address is dhchoe@kku.ac.kr.

In addition, the author's given name should be Dae-Hyun (i.e. Dae-Hyun Choe).

The online version of the original article can be found at http://dx.doi.org10.1007/s10610-013-9216-4.

D. H. Choe $(\bowtie)$

Konkuk University, 268 Chungwon-Daero, Chungju 380-701, South Korea

e-mail: dhchoe@kku.ac.kr 